\title{
Workshop on WHO Framework Convention on Tobacco Control to promote the Protocol to eliminate illicit trade in tobacco products
}

Citation: Workshop on WHO Framework Convention on Tobacco Control to promote the Protocol to eliminate illicit trade in tobacco products. East Mediterr Health J. 2018;24(1):111 https://doi.org/10.26719/2018.24.1.111

Copyright (C) World Health Organization (WHO) 2018. Some rights reserved. This work is available under the CC BY-NC-SA 3.0 IGO licence (https://creativecommons.org/licenses/by-nc-sa/3.o/igo).

Illicit trade in tobacco products is a significant concern in the Eastern Mediterranean Region (EMR). Reliable data on its size in each country are not available, and many EMR Member States do not have any reliable estimates on the illegal trade or the proper measures to fight it. To address this, a regional workshop was held in Amman, Jordan, 16-18 May 2017, with the WHO Framework Convention on Tobacco Control (FCTC) secretariat and WHO Regional Office for the Eastern Mediterranean (WHO/EMRO). The workshop pursued the following objectives:

- Strengthen technical and procedural steps at national level to ratify and implement the Protocol.

- Acquire those skills to implement the Protocol in a multi-sectoral approach.

- Improve coordination at national level and with key international players to confront illicit tobacco trade.

- Raise awareness among government officials on the consequences that illicit trade in tobacco products has on public health, finance and security in the Region.

- Address questions from the Member States related to the implementation of the Protocol.

The meeting was attended by 11 Member States (Afghanistan, Egypt, Islamic Republic of Iran, Iraq, Jordan, Lebanon, Libya, Pakistan, Sudan, Syrian Arab Republic and Tunisia) and the regional office of the Framework Convention Alliance. Two members of the Expert Panel on the Protocol gave presentations and shared their experience. While all 11 attendees are Parties to the WHO FCTC, only Iraq and Saudi Arabia have so far adhered to the Protocol.

The Region lacks data on illicit tobacco trade and any data available are provided by the tobacco industry. Thus, a neutral source of data is required. A major obstacle identified is the tobacco industry offering countries its own "solutions" for combatting illicit tobacco trade, arguing that this makes the Protocol unnecessary. Moreover, the tobacco manufacturing companies are sometimes state-owned, which creates conflicts of interests, while political instability and related crises are obstacles to combatting illicit tobacco trade effectively. Importantly, some countries admitted hesitancy in joining the Protocol since only two Member States so far had done this, and thus do not see becoming a party to the Protocol as a priority. However, ratifying the Protocol does not require any specific level of implementation of the WHO FCTC. Many representatives from the health sector also expressed their concerns regarding mobilizing their peers in ministries for the ratification and implementation of the Protocol, and the lack of a financially viable plan to do so. Here, it was proposed that the FCTC Secretariat and/or WHO/EMRO could communicate the importance to the various stakeholders, while the FCTC Secretariat and WHO/EMRO reminded that the Protocol would come into force only after 40 countries have ratified it, and is subject to a five-year timeline for implementation, allowing time for an affordable implementation strategy. The cost of the tracking and tracing (TT) systems required by the Protocol can be borne by the tobacco industry. Explanations of how tobacco products are smuggled, the interests of the tobacco industry to engage in such activities in parallel to legal sales, and the deterrent power of fines, were also outlined.

\section{Recommendations}

The workshop ended with an agreement on a set of recommendations for the Parties, the FCTC Secretariat and the WHO/EMRO Tobacco Free Initative (TFI), as follows:

- The Parties were encouraged to start the ratification /accession process as soon as possible, using a multisectoral approach, and soliciting assistance where needed.

- A specific focus was given on deflecting interference from the tobacco industry - a particular challenge in countries with State-owned tobacco companies.

- The FCTC Secretariat and the WHO/EMRO TFI were encouraged to provide the technical and, where possible, financial assistance to support the Parties.

- The FCTC Secretariat and the WHO/EMRO TFI were encouraged to disclose the tactics of the tobacco industry and to take advantage of high level meetings such as the World Health Assembly (WHA) to promote the entry into force of the Protocol. 